\title{
Empirical impact of Electricity Outage on Labour and Capital Productivity in Nigeria
}

\author{
Osinachi Iroh ${ }^{1, *, \dagger}$, Ijeoma Kalu ${ }^{1, \dagger}$ and Alwell Nteegah ${ }^{1, \dagger}$ \\ ${ }^{1}$ Energy Economics, Emerald Energy Institute, University of Port Harcourt, Port Harcourt, Nigeria \\ *corresponding author: osy-iroh@yahoo.com \\ ${ }^{\dagger}$ Auhtors Contributed equally.
}

\begin{abstract}
Background: This study empirically examined the impact of electricity power outages on Nigeria's capital and labour productivity. The emphasis is on how frequent electricity outage reduces labour and capital effectiveness and other factors of production. Methodology: To achieve the above objective, annual time series data on Total Factor Productivity - a proxy for Nigeria's factors productivity, Power Outage (electric power transmission and distribution losses as \% of output), and other controlled variables were used to estimate the relationship and all data were from World Bank Development Indicators (WDI). The Fully Modified Ordinary Least Square (FOLS) technique was adopted for analysis. Findings: The empirical results showed a negative relationship between power outages and factor productivity. The result also reveals that electricity pricing has a significant negative impact on the factor productivity while both electricity generation and population have a significant positive impact on Nigeria's total factor productivity. The implication is that the substitution effect between labour and capital is positive, meaning that Nigeria exhibits a labour-intensive production function. In conclusion, the study is of the opinion that power outage and electricity pricing negatively impact factors productivity while electricity generation and population have a positive relationship with factors productivity in Nigeria.
\end{abstract}

Key words: Corruption, DISCOs, Energy Generation, Energy Pricing, Power Outage.

\section{Introduction}

Electricity blackout and its implication on factor productivity have remained an issue that has generated widespread discussion among academicians and policy experts, particularly in developing countries (Tonuchi; 2019). The increased discussion of electricity blackout stems from the prominent role energy plays in any nation's development and growth. Tonuchi (2019) opined that energy is the fifth factor of production, without which all other production factors will remain unutilized or underutilized. To Cissokho and Seck (2013) energy is the wheel that drives any nation's economy to the part of prosperity. To this end, the availability or unavailability of energy impacts the nation's productivity and the level of consumption of the nation.

Literature suggests that the higher the country's economic activities, the higher the volume of energy required to support the high volume of economic activities. Similarly, the higher the available energy to drive production factors, the higher the country's economic activities (Tonuchi; 2019; Okeke; 2016). This is evidenced in cross-country analysis, where developed and advanced countries' volume of energy consumption outweigh that of the developing countries (IEA; 2020). International Energy Agency (IEA (2020)) report revealed that advanced countries with similar population figures as that of developing countries consume at least twice the electricity or energy consumption of developing countries with a similar population. Similarly, countries with high total factor productivity consume more electricity than countries with lower total factor productivity (Imandojemu and Joseph, 2021) (Imandojemu and Joseph; 2021).

Given the established relationship between electricity 
consumption and rising economic activities, one common concern has always been what is the impact of the frequent blackout of electricity on factor productivity, particularly labour and capital? The answer to the above question starts with understanding the electricity supply and distribution value chain dynamics. As argued by Ibitoye and Adenikinju (2017), the Nigerian power sector is plagued by several structural issues, including but not limited to generation deficiency, supply linkages, transmission, and distribution defects. Others include chronic vandalism of oil and gas pipelines, infrastructural deficiency, corrupt practices by both the distribution companies' staff and the public. Underinvestment in maintenance and infrastructure has constrained the transmission grid. Finally, high collection and commercial losses have impacted the financial viability of the privatized distribution companies (Iwayemi; 2018).

IEA (2020) estimated that electricity outages and energyrelated crises plaguing most African countries had constrained the continent from achieving significant and meaningful development and growth levels. Andersen and Dalgaard (2013) noted that an erratic and constant electricity outage is the leading challenge facing most businesses in Nigeria, according to the world bank enterprise survey. The survey revealed that power supply constraint is the major problem facing more than 50 percent of the firms that responded to the survey, followed by access to finance (World-Bank; 2020). Imandojemu and Joseph (2021) argued further that power outages in Nigeria contributes to more than 30 percent of firms failure because of the rising overhead cost. While the central bank of Nigeria (CBN) has made several efforts to increase access to finance by enterprise by introducing different special intervention funds targeting different sectors of the country, little or nothing has been done to reduce electricity blackout. Though, Imandojemu and Joseph (2021) argued that CBN also target the DISCOS and other energy generated firms to increase electricity availability, much have still not been achieved in terms of constant electricity supply in Nigeria and this has cripled several firms and force their employees (labour) and resources (capital) to remain idle when they aught to be active. Tonuchi et al. (2020) noted that manufacturing firms' average capacity utilization had hovered around 45 percent for the past three decades, and one possible explanation for these ugly trends in the frequent electricity blackout in the country and lack of poor access to credit by firms that have left most of the firms' factor inputs unutilized. This constant blackout has led several firms to resort to selfgenerating electricity, which has affected their overhead cost and their sales volume as their products are no longer competitive in the international market (Imandojemu and Joseph; 2021). World-Bank (2020) projected that about 25 percent of Nigeria's potential GDP is lost to an erratic power supply. While few studies have investigated the issue, literature still share divided view about the exact relationship between power outages and economic growth. To this end, this paper investigates the impact of electricity blackout on Nigeria's productivity. The rest of the paper is organized as follows: Section 2 provides a review of related literature. Section 3 discusses the methodology, while section 4 provides data and result discussion. Lastly, section 5 concludes and provide policy implication.

\section{Literature Review}

\subsection{Conceptual Review}

This sub-section provides brief review and discussion of key concepts relating to electricity blackout and factors productivity. The concept of electricity blackout is often used interchangeably as a power cut, power outage, and power failure in most literatures (Andersen and Dalgaard; 2013; Okeke; 2016; Tonuchi; 2019) . Most of these literature often describes electricity blackout as the loss of electricity power supply to a particular end-user. Tonuchi (2019) referred to an electricity outage as a situation where individuals, households, and firms who require and are willing to pay for the supply of electricity cannot access it. However, Andersen and Dalgaard (2013) made an effort to distinguish electricity blackout from a power outage when the authors noted that electricity blackout is a complete loss of electricity supply to an area. The author further noted that while power outages often last for a few weeks' electricity blackouts last for months. Electricity blackout creates serious economic hardship both for the households and the firms in general (Adewuyi and Emmanuel; 2018; Akuru and Okoro; 2014).

Adenikinju (2005) shared the view that electricity blackout creates economic hardship to the household in the form of dark night, burning of electronic appliances, and the firms often faces constraints blackouts that impact production. This often creates a situation where the household and the firms often result to self-generating electricity, which is often very costly and unfordable. Such incidence creates a situation where domestic investment is constrained and eventually crowding out domestically (Tonuchi; 2019). It was the biggest challenge identified to be facing medium and large firms in the 2018 enterprise survey conducted by the World Bank (World-Bank; 2020).

A closer examination of the survey as presented in Figure 1 revealed that Nigerian firms identify electricity blackout or outage as the second biggest threat to their survival a little margin below access to finance. The survey further revealed that Nigerian firms, on average of 38.9 percent of the time in a typical month experiences a power outage, which has created a percentage value loss of more than 11 percent for a typical month in sales volume. Figure 2 further revealed that 42.2 percent of large firms in Nigeria identified Electricity blackout or outage as the biggest challenges facing their existence in the country. As noted by Tonuchi (2019), electricity outage has a serious negative effect on firms in the form of damages to their technology, underutilization of resources, increasing operating costs as firms self-generate electricity. Other issues identified are that high electricity blackout makes the firm's product less competitive with other products from neighboring countries. It hinders the effective and efficient administration of technology in the country. (Joseph; 2020) argued that frequent power outages due to infrastructural decay is one reason why so many firms remain in the informal sector and advocated for more investment in the infrastructure to guarantee more technology adoption in the financial system in solving the problem of Covid 19.

Data from the World Bank revealed that Nigeria ranked top among countries with low access to electricity. The average access to electricity percentage of the population for West Africa is above Nigeria's average, the currently only managed to average above sub-Saharan African countries excluding highincome countries. As revealed in Figure 3, the OECD countries have achieved almost 100 percent electricity access percent of the population, an indication that countries with low electricity blackout will have higher access to electricity and a higher level of productivity and growth. 


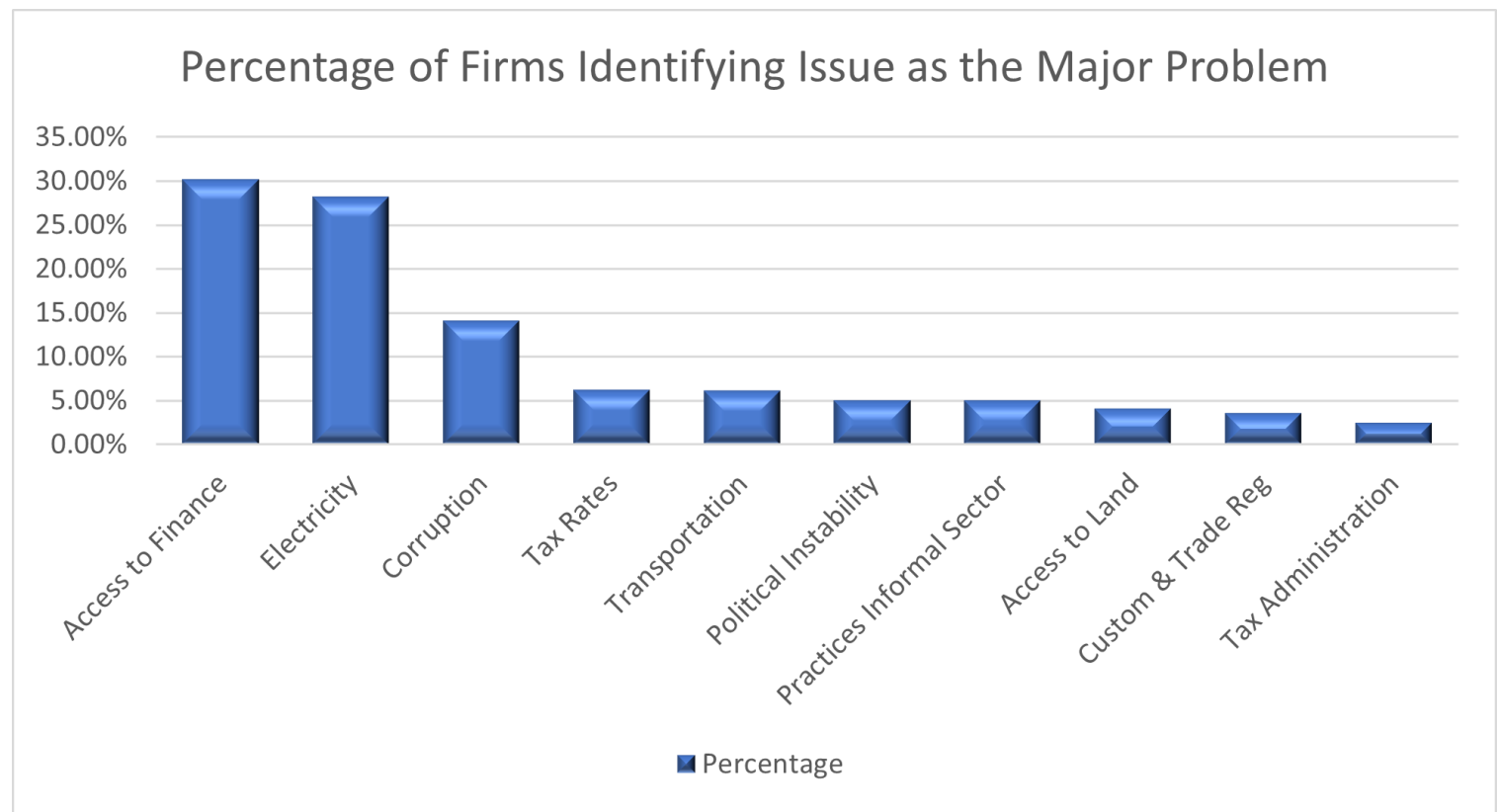

Figure 1. Nigeria Firms Biggest Challenges in Percentage

Source: Researcher using data form World Bank Enterprise Survey 2018

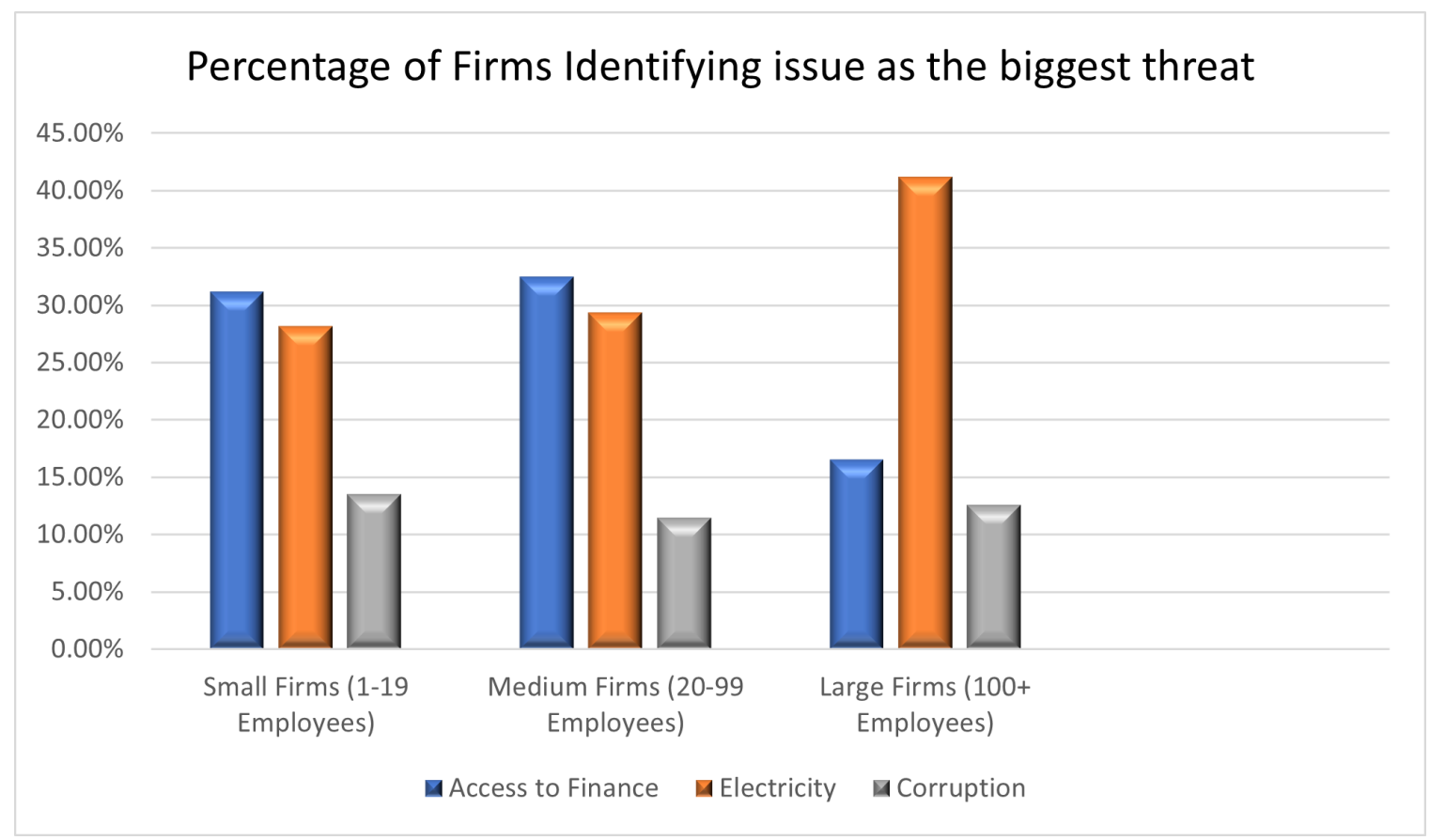

Figure 2. Classification of Challenges Facing Nigerians Firms by Size Source: Researcher based on World Bank Enterprise Survey 


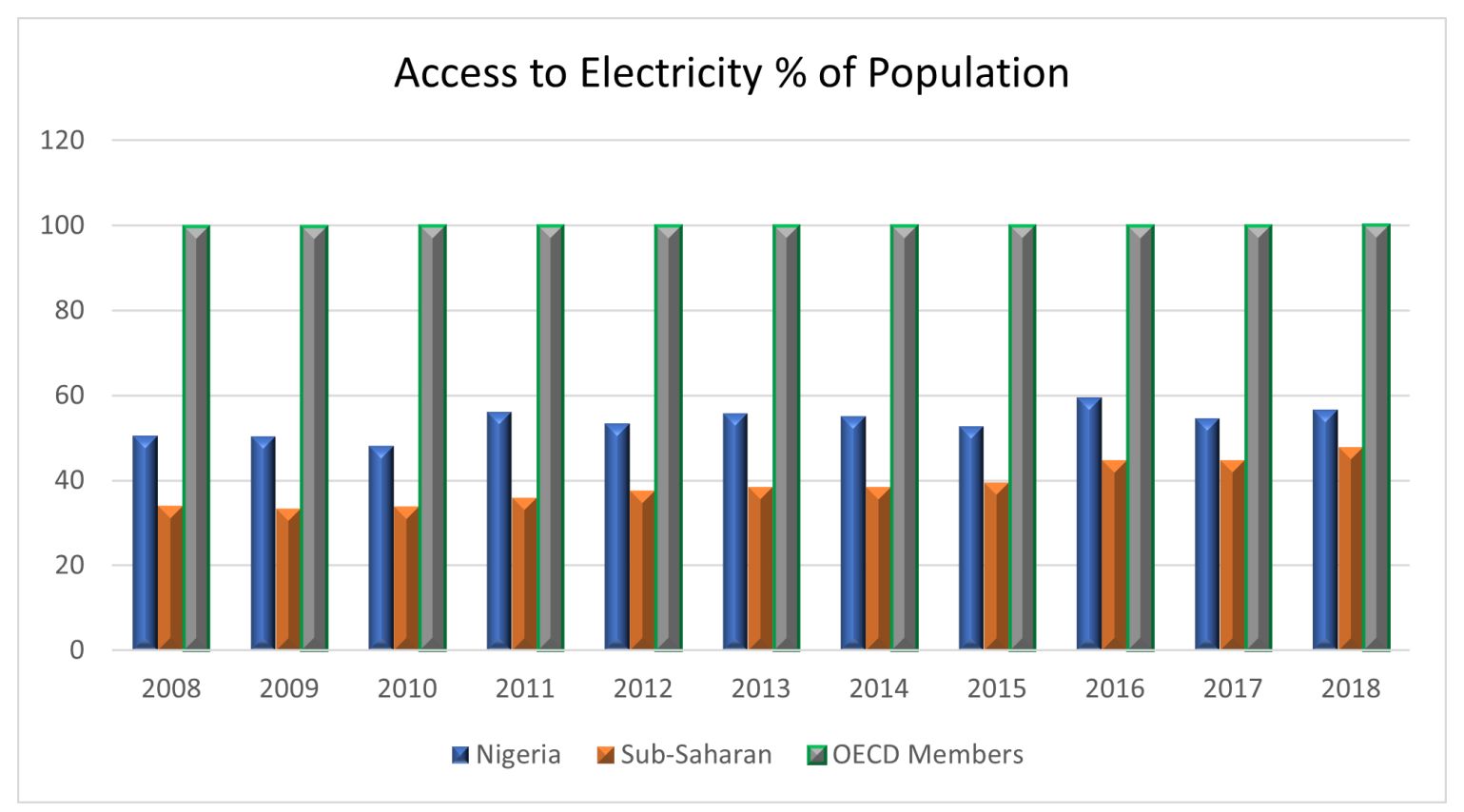

Figure 3. Access to Electricity Indicators

\subsection{Empirical Review}

The cost of an electricity outage and blackout on Nigeria's economy both at a macroeconomics or microeconomics level has been discussed over time. One of the first attempts to empirically investigate the cost of electricity outages on Nigeria's economy is the work ofAdenikinju (2005). The author investigated the impact of electricity failure in developing countries with a particular focus on Nigeria. The study employed a survey method where manufacturing establishments were sampled with regards to the extent electricity supply constraints their output. It was discovered that poor electricity supply has increased the manufacturing firms' overhead cost as they often resort to self-generating electricity to cushion the effect of electricity blackout in the country. The author further discovered that small-scale enterprises are the major hit as it is often difficult for the enterprise to fund the self-electricity generation and when they do, it usually take a large chunk of their investment. Although, Tonuchi (2019) investigation on the potential of renewable energy in meeting the electricity demands of rural communities in the riverine area of Niger Delta. It was discovered that conventional electricity generation through hydroelectricity is the most cost effective followed by electricity generation through biomass while solar energy generation is the most expensive. The author argued that self-generating electricity through biomass is cost-effective and serves as the best alternative to a frequent power outage in the country. However, the author is quick to point out that self-generating electricity is capital intensive and poses difficulties to Small scale enterprises to fund such projects.

A similar stance was shared by Akuru and Okoro (2014) that investigated the impact of epileptic power supply on Nigeria economy with focus on the performance of the SMEs. Using descriptive and exploratory analysis, the study concluded that electricity outage impacts the SMEs more severely and has contributed to the country's leading cause of SMEs failure. The study further argued that constant power failure had created an energy crisis both within the households and the industrial sector of Nigeria due to the inability of the distribution companies to meet electricity demands. Still, within the microeconomic level, Adewuyi and Emmanuel (2018) conducted an extensive study to see if corruption plays any effective role of the relationship electricity outage on firms' performance across the six geo-political in Nigeria. Particularly the study made an effort to further investigate the impact of self-electricity generation on the firm's performance across the geo-political zones in the country. The study particularly used the World Bank Enterprise Survey data, ordinary least square, and Two -Stage-Least-Square techniques to estimate the relationship. It was discovered that bribery does not play any significant role in the nexus between electricity outage and firm performances across the six geo-political zones except for south-east and north-east.

The study further argued that self-generating electricity by the firms have a negative impact on their performance in three geo-political zones including south-west, north-west, and south-south while other geo-political zone achieves positive result using self-generating electricity. Although the study failed to explain the mix findings, while self-generating electricity should improves the performances of the firms while it does not improve the performances of the firm in other zones. Are there variables the survey omitted that can explain the differences in the impact of self-generating electricity on the firm performance? A similar study was conducted by Hunt et al. (2016) who conducted the effect of electricity shortages on Indian manufacturing firms. The study instrumented electricity shortages using supply shifts from hydroelectric power availability. It was discovered that the electricity shortage in India manufacturing firm raises their average plant's revenues and producer surplus by 5 to 10 percent. The study provides significant evidence that poor electricity supply impacted the firms' capacity utilization increase their average overhead cost through rising generator cost/ self-electricity generation. Arlet (2017) find a similar outcome to that of Hunt et al. (2016) when the author investigated the impact of electricity outage and electricity tariff on the performance firms using descriptive survey data from 190 countries. Like most previous studies focusing in Nigeria or only Sub-Saharan African countries, the study found a negative impact of electricity outage on firm's performance 
within the period under study. The study was silent about the role of tariffs in reducing the electricity shortage or its role in mediating the nexus between electricity outage and firm's performance. Several other studies have equally found a negative relationship between electricity outage or blackout and firms' performance (Abeberese; 2017; Mensah; 2016), or on the economy and household (Rud; 2012; Cissokho and Seck; 2013).

Pless and Fell (2017) particularly focused on ascertaining if bribery played any meaningful role on electricity reliability. Using cross-sectional data, the revealed among others that incessant and frequent power outage increases the likelihood of the firms bribe the electricity officials to increase electricity supply in their region or industrial area. The study also argued that electricity supply failure bribery increases the likelihood of electricity outage for at least 14 times per month. It was equally discovered that electricity outage prominence reduces the firm's revenue negatively and the overall effect of power outage on global output is about 14 percent.

At a macroeconomic level, several studies have also investigated the power outage and economic growth of Nigeria. For instance, Joseph and Adebayo (2012) investigated the economic consequences of power outages on the household, commercial, and industrial consumers in Nigeria. The study employed the Vector Autoregressive (VAR) techniques to estimate the relationship. The study concluded that power outage negatively impacts household income, industrial output, and economic growth in the country. The study argued that the issue of electricity sector reforms from both the generating companies (DISCOS) and distribution companies (DISCOS) is not holistic and should be made more flexible to accommodate deregulation. The study application of VAR to estimate impact relationship has some element of methodological weakness as VAR is best suited for establishing any existing relationship. A similar stance was shared by Andersen and Dalgaard (2013) when the authors estimated the effect of power outages on economic growth in Sub-Saharan Africa within the period of 1995-2007. The findings revealed that power outage impacts output in Sub-Saharan Africa countries negatively and advocated for more investment in infrastructural development to drive the nations' economic growth. The study argued that power outage reduces the Sub-Saharan countries' output by at least 10 percent, which is significant for countries still on the part of development.

George and Oseni (2012) evaluated the impact of electricity outputs, supply, and consumption in solving the high rate of unemployment in Nigeria using time series data from 1970 to 2005. The study employed ordinary least square regression model to estimate the relationship between power supply and unemployment. It was discovered that power supply has power supply failure has significant positive relationship with unemployment rate in the country. Indicating that rising power supply failure induces labour and capital unproductivity, which increases the country's unemployment rate. Imandojemu and Joseph (2021) investigated the electricity blackout and Nigeria productivity using fully modified OLS. It was discovered that electricity blackout had a negative effect on the productivity level of Nigeria. The coefficient indicates that a one percent increase in electricity blackout will leads to a 104 percent decrease in productivity. It was equally revealed that electricity price has negative impact on productivity. Electricity generation and population have positive impact on productivity. The study also argued that corruption plays a major role in the relationship between power outage and Nigeria productivity.
Overall, most of the previous studies, either at national, regional or on a global scale on electricity outage have focused either on its impact on the economic growth or its impact on firm output. The common estimation technique employed in literature to investigate the issue is ordinary least square (OLS) regardless of the several econometrics flaws with OLS. Similarly, growth equation often suffers from endogeneity issues because of a bi-causal relationship between variables of interest, which OLS will not be able to solve. While a robust estimation test for OLS can resolve some of the other estimation issues like serial correlation, the issues of endogeneity and heteroskedasticity cannot be solved by OLS. Thus, this study will mitigate such issues by employing an estimation technique like Fully Modified OLS (FMOLS) that has the ability to mitigate the above-listed issues to investigate the relationship.

\section{Methodology}

\subsection{Theoretical Framework}

This study investigated the impact of electricity power outages on Nigeria's productivity. The theoretical foundation of the study is based on the Modified Solow growth equation as propounded by Mankiw et al. (1992) who argued that knowledge or technical progress does not enter the Solow model multiplicatively through labour and capital but are rather part of other factor inputs see (Joseph and Obikaonu; 2021). And Imandojemu and Joseph (2021) referred to it as the last stratum of Solow residual. Thus, the study, therefore, following the work of Imandojemu and Joseph (2021) argued that constant electricity outage will reduce the effectiveness of labour and capital which is captured by total factor productivity.

It is believed that frequent electricity blackouts or power outages will cause the most critical production factors (labour and capital) to lie idle and remain underutilized. The argument is clear when there is a lack of sufficient energy supply either from the conventional electricity generation or through self-generating electricity most of the production factors will lie idle and unproductive because there is no energy to power the machine through which the labour operates. In such circumstances, the labour and capital lie idle for hours waiting for electricity supply, particularly for SMEs, and in some other cases, the firms reduce the organisation operation to the capacity of the self-generating electricity. This will reduce the capacity utilization of the firms and particularly reduce their output (Imandojemu and Joseph; 2021).

Similarly, a frequent power outage tends to increase the cost of production as firms tend to source energy from other non-conventional electricity through self-generating sources. Such moves have two major concerns, the first being that selfgenerating electricity is more expensive and secondly, selfgenerating electricity tends not be environmentally friendly as most are generated through generators using gas and fuel. Thus, the extent of frequent electricity outage impacts on Nigeria's productivity has not been effectively evaluated in previous literature. It is believed that energy serves as both factor of production as well as an enhancer of other factors of production. Its availability can effectively increase the efficiency of other factors of production. Adewuyi and Emmanuel (2018) argued that electricity is a production input that enhances other production factors, and therefore provide an argument that countries with a high and stable supply of electricity enjoys high total factor productivity since all factors of production are en- 
Table 1. Stationarity Test Using ADF statistics

\begin{tabular}{l|llll}
\hline Variables & ADF @ Level & ADF at 1st Diff & t-Statistic & Order of integration \\
\hline LnPO & $-2.283839^{*}$ & $-7.147833^{* * *}$ & -3.50851 & $\mathrm{I}(1)$ \\
LnEneP & $-2.628284^{*}$ & $-6.535675^{* * *}$ & -3.51074 & $\mathrm{I}(1)$ \\
LnEneG & $-2.146327^{*}$ & $-7.245633^{* * *}$ & -3.50637 & $\mathrm{I}(1)$ \\
Lnpop & -0.524363 & $-4.459832^{* * *}$ & -3.51074 & $\mathrm{I}(1)$ \\
LnTFP & $-2.156277^{*}$ & $-5.626474^{* * *}$ & $-3.50851 \mathrm{I}(1)$ & \\
\hline
\end{tabular}

All variables are logged and Significance is indicated as follows: $* * *, * *$ and $*$ for $1 \%, 5 \%$ and $10 \%$ respectively.

gaged at every opportunity.

\subsection{Model Specification}

As such, the study models the electricity and factor productivity relationship following the work of Adewuyi and Emmanuel (2018) and Imandojemu and Joseph (2021). Therefore, the model is represented symbolically in its functional form as:

$$
\mathrm{TFP}=f(P O, \text { EnerP }, \text { EnerG }, P O P)
$$

Where; TFP $=$ Total Factor Productivity PO = Power outage - Electric power losses (\% of output) EnerP = Electricity Pricing

EnerG = Electricity Generation

Pop = Population

The econometric form of the model is as presented in equation (1) below;

$$
\operatorname{lnTFP}=\alpha_{1} \ln \mathrm{PO}_{t}+\alpha_{2} \ln \text { EnerG }_{2}+\alpha_{3} \text { EnerP }_{t}+\alpha_{4} \ln P O P_{t}+\varepsilon_{t}
$$

where LnTFP is the log of total factor productivity (TFP) that used to proxy Nigeria's factors productivity, Electric power transmission and distribution losses (\% of output) is the proxy for electricity blackout (PO) while EnerG represents Electricity generation. Other variables like EneP represents Electricity price, and POP represent population. EneG, EneP, and POP were used as controlled variables in the model.

Theoretically, an increase in electricity outage will negatively influence the effectiveness of production factors since most of the factor inputs will lie unutilized or underutilized. Theoretically, we expect that the more the electricity generation, the higher the country's total factor productivity, since more energy generation will mean additional electricity is available to all households and firms (Tonuchi; 2019). Okeke (2016) has argued that electricity rationing because of insufficient supply is the major cause of frequent power outages in Nigeria, which means that the rise in electricity supply will increase productivity. The relationship between population and factor productivity depends on the substitution effects between labour and capital. Thus, the population can turn positive or negative depending on its usage.

\subsection{Estimation Technique}

This study employed the Fully Modified Ordinary Least Squares (FMOLS) that was developed by Philips and Hansen (1990) to estimate the existing relationship between power outage and factors productivity in Nigeria. FMOLS was primarily developed to solve structural and econometric issues with ordinary least square (OLS), particularly for estimating a single cointegrating relationship of order I(1). Tonuchi et al. (2021)) argued that FMOLS performs better and appears more consistent

\begin{tabular}{|c|c|c|c|c|c|}
\hline Variable & \multicolumn{4}{|c|}{\begin{tabular}{l|l} 
Test Statistic & $5 \%$ critical value
\end{tabular}} & integration \\
\hline Long (U1) & \multicolumn{2}{|c|}{$-5.747394^{* *}$} & \multicolumn{2}{|c|}{-3.510748} & $\mathrm{I}(0)$ \\
\hline \multicolumn{6}{|c|}{ 'able 2. Johansen Co-integration Test } \\
\hline \multicolumn{2}{|c|}{ Maximum Rank } & 0 & & 1 & 2 \\
\hline \multirow{2}{*}{\multicolumn{2}{|c|}{$\begin{array}{l}\text { Trace Statistics } \\
5 \% \text { critical value }\end{array}$}} & 137.2 & $38^{* *}$ & $87.4390 * *$ & 78.5367 \\
\hline & & 95.75 & & 69.8188 & 47.6738 \\
\hline
\end{tabular}
than ordinary least square in the presence of large sample bias.
Table 3. Residual term (U1) Stationarity test using ADF

Trace test indicates 3 cointegrating eqn(s) at the 0.05 level. $* *$ denotes rejection of the hypothesis at the 0.05 level

Among the top issues with the OLS estimation technique is the possibility of estimate bias due to the model suffering from heteroscedasticity and serial correlation common in timeseries data. Such bias resulting from the serial correlation is mostly accounted by the error of omission captured in the residual thereby impacting the standard error's true size. Such issue could be easily resolved using FMOLS and its counterpart dynamic OLS (DOLS). It includes the leads and lags of the endogenous variables in the model and resolves the issue endogeneity that is common in most growth related equation. A major limitation with FMOLS as compared to Auto Distributed Lag Model (ARDL) is that it is best used for time series of same order of integration particularly of order one that it I(1) (Imandojemu and Joseph; 2021). To this end, the study will first establish the existence of stationarity of the time series before applying FMOLS.

\subsection{Data and Sources}

The study relied mainly on data from World Bank Development Indicators (WDI) 2019 and central Bank of Nigeria (CBN). Ukoima et al. (2019), proxied electricity price with the ratio of electricity revenue to the Nigeria's population and this present study will follow the author's approach. As stated earlier, the corruption perception index developed by transparency international was used to capture the level of corruption in the electricity distribution companies' value chain in Nigeria.

\section{Results and Discussion}

This section presents and discusses the result of the findings based on the model presented in the methodology section.

\subsection{Stationarity/Unit root Test}

Augmented Dickey Fuller test was primarily used to test for the presence or absence of a unit root in each of the time series as presented in Table 1 . The findings revealed that 
Table 4. FMOLS results

\begin{tabular}{|l|l|}
\hline \multicolumn{1}{|c|}{ Variables } & \multicolumn{1}{c|}{ Coefficient (p-value) } \\
\hline Lag of TFP & $0.934(0.0000)^{* * *}$ \\
\hline Log of Energy price & $-0.3261(0.0151)^{* * *}$ \\
\hline Log of Energy generation & $0.5435(0.0135)^{* * *}$ \\
\hline Log of population & $2.2146(0.0045)^{* * *}$ \\
\hline Constant & $0.3253(0.0125)^{* * *}$ \\
\hline R-square & 0.7831 \\
\hline
\end{tabular}

Significance is indicated as follows: $* * *, * *$ and $*$ for $1 \%, 5 \%$ and $10 \%$ respectively, p-value in parenthesis.

none of the series of interest is stationary at level given that their ADF value is less than the $5 \%$ critical value. However, on differencing the series all became stationary at first difference. Given that all the variables are stationary after their first difference, it further reaffirms the choice of FMOLS in investigating the relationship between an electricity power outage and factors productivity in Nigeria. The study will borrow leave from the work of Tonuchi et al. (2021), by making a further effort to establish the existence of long-run relationship between the series under investigation. Tonuchi et al. (2021) and Imandojemu and Joseph (2021) argued that differencing a variable lead to the loss of information on the long-run relationship and requires that researcher make extra efforts by testing the existence of long-run relationships among the series under investigation before estimating the equation.

As such, this study applies the Eagle Granger two-step approach to estimate the existence of long-run relationships among the series. The step involves first estimating the relationship equation (1) without including constant among the exogenous variables to ensure the variables represent deviation from their means. The second step is, therefore, to subject the residual term to a unit root test. The result of the second step of the unit root test is as presented in table 2 .

The result from Table 2 clearly indicates the existence of long-run relationship among the series given that the ADF test at level is greater than the $\mathrm{ADF}$ at $5 \%$ critical value. The study further subjects the data to Johansen cointegration test to reaffirm the findings from the Eagle- Granger two step approach. From the Johansen co-integration test as presented in Table 3, it can be revealed that there are at least 3 co-integrating vectors, further validating the existence of long-run relationship among the series under investigation. To this end, long-run relationship has been established among the variables of interest. FMOLS presents the researcher's opportunities to either estimate the model with a difference version or an un-difference version. Either way, both often present similar output with no major difference, as such, the study estimates the model with a different version as presented in Table 4 .

The result in table 4 revealed among others that electricity outage has significant negative impact on factor productivity given that the $\mathrm{p}$-value $(0.024)$ is less than $5 \%$ (0.05) level of significance. Particularly, the result revealed that increasing the electricity power outage by one percent $(1 \%)$ will lead to about 103 decrease in Nigeria's factor productivity. This means that a the power outage is getting worse in the country, the country's productive level will also be worsened.

The findings are similar to Adewuyi and Emmanuel (2018) findings who discovered a negative relationship between a power outage and firms output. A possible explanation for the negative relationship between power outage and factors productivity is the reason given by Imandojemu and Joseph (2021) when they argued that electricity power outage creates a disruption in the organisation workflow which hinders the organisation's performance as most of the factors input lies idle because of electricity disruption. The model also revealed that electricity pricing (EneP) has a significant negative impact on the factor productivity at 5 percent level of significance, given that the $\mathrm{p}$-value $(0.0151)$ is less than $5 \%(0.05)$ critical value. In order words, an increase in the price of electricity by one percent will lead to about a 32 percent increase in the factor productivity. One possible explanation is that the rise in electricity pricing tends to increase the firms' overhead cost which will either reduce the firms' employment of other factors to control the cost of production or increase the price of the output. Therefore, the rise in the price of electricity has a way of reducing its demands or the existence of electricity rationing. Such activities will impact the effectiveness of production factors.

The model further revealed that electricity generation has significant positive impact on factors productivity. An increase in electricity production by one percent will lead to a 35 percent increase in the factor productivity as expected. Similarly, an increase in population also has a significant positive impact on the productivity of Nigeria's economy. The implication is that the substitution effect between labour and capital is positive, meaning that Nigeria exhibits labour-intensive production function. The findings is not unexpected as Nigeria's economy is primarily driven by small-scale agriculture farming or is dominated by peasant farmers.

However, contrary to expectation, the introduction of corruption in the model reduces the impact of electricity generation by 23 percent and the impact of population by over 100 percent. Although both electricity generation and population still maintain a significant positive impact on the productivity of the factors at 5 percent level of significance. The R-square for the two models is moderate and depicts that the model has a good fit.

\section{Conclusion and Policy Implication}

This study concludes that electricity power outage has a significant negative impact on production factors productivity within the sampled period. The implication is that frequent power outage as currently witnessed in most parts of the country will reduce the factor inputs' productivity. This disruption in the production process occasioned by electricity outage will naturally create damage to the workflows and create idle time in the production process. The time spent waiting for electricity to be restored back or the time it takes for the organizations that can self-generate electricity creates some shortages in the production process.

The policy implication is that the government needs to invest more in infrastructure to reduce electricity loss during the transmission stage and develop abilities and technologies to track every fraudulent activity in the DISCOs value chain. Similarly, the DISCOs can develop a more effective monitoring strategy to ensure the reduction of fraudulent practices in the distribution value chain. For instance, the Discos conventionally has marketers who monitor and are in charge of a particular jurisdiction for months or even years. Such practices encourage stealing, or susceptible bribery as the customers become much familiar with the marketers. One solution to such an issue is frequent monitoring staff covering a particular location at least once a month. This will make it impossible for customers to 
collaborate with staff to commit fraudulent practices. Lastly, DISCOs should be fully deregulated, and investors should be licensed to operate in more than one location to create competition in the country.

\section{Competing Interests}

Author declare no competing interests.

\section{References}

Abeberese, A. B. (2017). Electricity cost and firm performance: evidence from india, The Review of Economics and Statistics, MIT Press 99(5): 839-852.

Adenikinju, A. F. (2005). Analysis of the cost of infrastructure failures in a developing economy: The case of the electricity sector in nigeria, African Economic Research Consortium (AERC) 148: $1-38$.

URL: $h$ ttp://aercafrica.org/wp-content/uploads/2018/o7/RP148.pdf

Adewuyi, A. O. and Emmanuel, Z. (2018). Electricity outages and firm performance across the six geo-political zones in Nigeria: the role of corruption, Munich Personal RePEc Archive (MPRA).

Akuru, U. B. and Okoro, O. I. (2014). Economic implications of constant power outages on smes in nigeria, Journal of Energy in Southern Africa 11: 61-66.

Andersen, T. B. and Dalgaard, C. J. (2013). Power outages and economic growth in africa, Energy Economics 38: 19-23.

Cissokho, L. and Seck, A. (2013). Electric power outages and the productivity of small and medium enterprises in senegal, Investment Climate and Business Environment Research Fund Report 77: 13 .

George, E. O. and Oseni, J. E. (2012). The relationship between electricity power and unemployment rates in nigeria, Australian Journal of Business and Management Research 2(2): 1019.

Hunt, A., Allan, C. and Stephen, D. O. (2016). How do electricity shortages affect industry? evidence from india, American Economic Review (AER) 106(3): 587-624.

Ibitoye, F. I. and Adenikinju, A. (2017). Future electricity demand in nigeria, Applied energy 84(5): 492-504.

IEA (2020). World energy outlook 2020, International Energy Agency (IEA).

URL: https://www.iea.org/reports/world-energy-outlook-2020

Imandojemu, K. and Joseph, T. E. (2021). Contribution to the empirics of electricity blackouts and productivity in nigeria,

Mensah, J. T. (2016). Bring back our light: Power outages and industrial performance in sub-saharan africa, FAERE Working Paper 20(1).
Energy Economics Letters 8(1): 60-69.

Iwayemi, A. (2018). Investment in electricity generation and transmission in nigeria: issues and option, International Association for Energy Economics, First Quarter 1: 37-42.

Joseph, A. I. and Adebayo, O. E. (2012). Econometric analysis of the impacts of power outage on consumers in nigeria, Journal of business and Organisational Development 4: 1-11.

Joseph, T. E. (2020). How to improve mobile money service usage and adoption by nigerians in the era of covid-19, International Journal of Finance, Insurance and Risk Management $\mathbf{x}(3): 31-52$.

Joseph, T. and Obikaonu, P. (2021). Economic growth and quality adjusted human capital equation: Moderating role of social capabilities in africa, Applied Journal of Economics, Management and Social Sciences 2(2): 1-9.

Mankiw, N. G., Romer, D. and Weil, D. N. (1992). A contribution to the empirics of economic growth, The Quarterly Journal of Economics 107: 407-437.

Okeke, E. O. (2016). Analysis of renewable energy potentials in nigeria for national development, International Journal of Engineering Research and Reviews 4(2): 15-19.

Pless, J. and Fell, H. (2017). Bribes, bureaucracies, and blackouts: Towards understanding how corruption at the firm level impacts electricity reliability, Resource and Energy Economics 47: 36-55.

Rud, J. P. (2012). Electricity provision and industrial development: Evidence from india, Journal of development Economics 97(2): 352-367.

Tonuchi, E. J. (2019). Investigating renewable energy potentials in solving energy crisis in niger delta riverine communities, nigeria, International Journal of Research in Electronics and Computer Engineering 7(3): 905-915.

Tonuchi, E. J., Idowu, P., Adetoba, O. O. and Mimiko, D. O. (2020). How large is the size of nigeria's informal economy? a mimic approach, International Journal of Economics, Commerce, and management VIII(7): 204-227.

Tonuchi, E. J.and Nwolisa, C. U., Obikaonu, P. C. and Alase, G. (2021). Monetary policy effectiveness and financial inclusion in nigeria: Fintech, 'the disrupter' or 'enabler', International Journal of Applied Economics, Finance and Accounting 9(1): 19-27.

Ukoima, K., Ekwe, O. and Agwu, E. O. (2019). Impact of electricity supply on economic growth: A nigerian case study, IOSR Journal of Electrical and Electronics Engineering (IOSR-JEEE) 14(1): 24-34.

World-Bank (2020). Doing business - Measuring Business Regulations, World Bank.

URL: https://www.doingbusiness.org/en/data/exploreeconomies/nigeria 